\title{
Sorptive Technology of Extracting Nonferrous Metals from Pit Water
}

\author{
K. L. Timofeev ${ }^{a}, *$, S. S. Naboychenko ${ }^{b, * *}$, A. B. Lebed ${ }^{b, * * *}$, and L. F. Akulich ${ }^{b}$ \\ ${ }^{a}$ OAO Uralelektromed, ul. Lenina 1, Verkhnaya Pyshma, Sverdlovsk oblast, 624091 Russia \\ *e-mail: k.timofeev@elem.ru \\ ***e-mail:mgi@elem.ru \\ ${ }^{b}$ Ural Federal University, ul. Mira 19, Yekaterinburg, 620002 Russia \\ **e-mail:mhnfm@mail.ustu.ru; s.a.petrova@ustu.ru
}

\begin{abstract}
Mine waters containing dangerous heavy metals are a significant environmental problem. Traditional methods of purification do not make it possible to completely eliminate impurities. In this work, the results of sorptive studies into the recovery of nonferrous metals from the mine water of a copper-zinc deposit are presented. Laboratory experiments for the selection of the optimal material and extended tests for the selected sample of a Lewatit TP 207 ion exchanger were performed. The possibilities of using ion exchangers to eliminate ions of heavy nonferrous metals are presented, and their capacity and selectivity indices relative to the sorption of nonferrous metals are determined.
\end{abstract}

Keywords: ion exchange, environmental protection, mine waters, ionites, recovery, copper-zinc deposit, sorption of nonferrous metals

DOI: $10.3103 / \mathrm{S} 1067821213010239$

Mine waters containing ore elements with toxic elements are a serious problem for mining enterprises of nonferrous metallurgy. Ores from complex deposits contain metals such as $\mathrm{Cu}, \mathrm{Zn}, \mathrm{Mn}, \mathrm{Ag}, \mathrm{Ba}$, and $\mathrm{Au}$ and traces of $\mathrm{Cd}, \mathrm{As}, \mathrm{Sb}, \mathrm{Hg}$, $\mathrm{Se}$, etc.

The oxidation of sulfide minerals is accompanied by an increase in temperature and the formation of sulfuric acid in large amounts. Water solutions become acidic and highly aggressive. Quarry and underspoil (mine) waters that are formed as copper-zinc ore deposits are mined are preliminarily neutralized with lime slurry and discharged into accumulating ponds and then to natural ponds. However, due to the extended anionic composition of waste waters, this method does not make it possible to attain sufficient purification [1].

A more complete recovery of metals is ensured by a sorptive method with the use of ion exchange resins that are widely used in water preparation [2]. When cationites were used, a high degree of removal of cations was attained, but, at the same time, low selectivity was observed [3]. Selective complex-forming ion exchangers are more promising for the recovery of heavy metals. The main difficulty in the sorptive recovery of nonferrous metals is the recovery of zinc ions, because copper is eliminated fairly easily using ion exchangers with amino groups [4].
In this study, the results of laboratory and extended tests of the sorptive post-treatment of mine waters previously neutralized with lime are presented.

The selection of the optimal ion exchanger in static and dynamic conditions and the technological calculations were done according to standard procedures [5]. Natural zeolites, sulfo- and carboxyl cationites, and complex forming anionites and ampholytes in different forms of the charge were used.

The purified starting solutions and eluates were analyzed after desorption according to atomic absorption and voltammeter methods using Analyst 100 (PerkinElmer) and TA-4 devices. The results were processed using Microsoft Excel 2007 software.

The contents of the samples of starting waters were as follows, $\mathrm{mg} / \mathrm{dm}^{3}: 0.05-1.01 \mathrm{Cu}, 10.34-36.4 \mathrm{Zn},<$ $0.05 \mathrm{Fe}, 305.4-475.6 \mathrm{Ca}$, and $54.9-136.2 \mathrm{Mg} ; \mathrm{pH}=$ $6.8-7.9$.

The main cations involved in ion exchange are calcium and zinc. According to the tabulated data on the separation coefficient $\left(D_{\mathrm{Zn} / \mathrm{Ca}}\right)$, the Purolite S984 ion exchanger is the most selective relative to zinc. However, the capacity for this ion exchanger is somewhat lower than for aminocarboxyl ion exchangers.

Based on these results, the following selectivity row of ion exchangers by zinc was determined: Tulsion CH-90 > Lewatit TP-207 $\left(\mathrm{Na}^{+}\right)$Monoplus XL > 




Fig. 1. Resulting sorption curves for zinc. (1) ANKB-35, (2) Purolite S930, and (3) Lewatit Tp-207. The arrows show the addition of a new portion of the solution.

(Purolite S930 Plus Purolite S984 Lewatit TP-207 $\left(\mathrm{H}^{+}\right)$Monoplus XL) $>$ANKB-35 $\gg($ KU-23 Amberlite IR-12 VP-1p $\sim$ Tulsion CXO-12MP $\sim$ KFGM-7).

It is obvious that a more efficient sorption of $\mathrm{Zn}$ is observed in ion exchangers in which complex formation due to coordination with amides (IDA resins and polyamide anionites) is achieved. It is of interest to use polyamine anionites to recover zinc, but because zinc has worse coordination characteristics than copper, it is more preferable to use amine carboxyl ampholytes (ANKB-35, Lewatit TP-207, Purolite S930) because the combined sorption (complex formation and ion exchange) will be achieved in this case.

At the next stage of our study, these ion exchangers underwent dynamic testing.

The source water was fed upward from pressure capacities to a sorptive column at a constant rate of $4 \pm$ 1 specific volumes of ion exchanger per hour. The volume of the charged sorbent was $25 \mathrm{~cm}^{3}$. The chemical composition of the purified water was monitored for content of $\mathrm{Cu}, \mathrm{Zn}, \mathrm{Fe}, \mathrm{Ca}$, and $\mathrm{Mg}$ after each 100 specific volumes.

The complete saturation of resins by zinc occurred when 1690, 1690, and 3130 specific volumes of ANKB-35, Purolite S930, and Lewait TP-207, respectively, were passed. The resulting sorption curves for zinc are presented in Fig. 1.

All the tested samples confirmed their high selectivity for copper, and no breakthrough $\left(<0.001 \mathrm{mg} / \mathrm{dm}^{3}\right)$ was observed.

The sorption of zinc was less efficient. For ANKB-35 $\left(\right.$ FDEC $\left.=29.16 \mathrm{~g} / \mathrm{dm}^{3}\right)$ and Purolite S930 $($ FDEC $=$ $\left.32.6 \mathrm{~g} / \mathrm{dm}^{3}\right)$, the zinc content in all analyzed samples exceeded the required MAC $\left(0.01 \mathrm{mg} / \mathrm{dm}^{3}\right)$, although

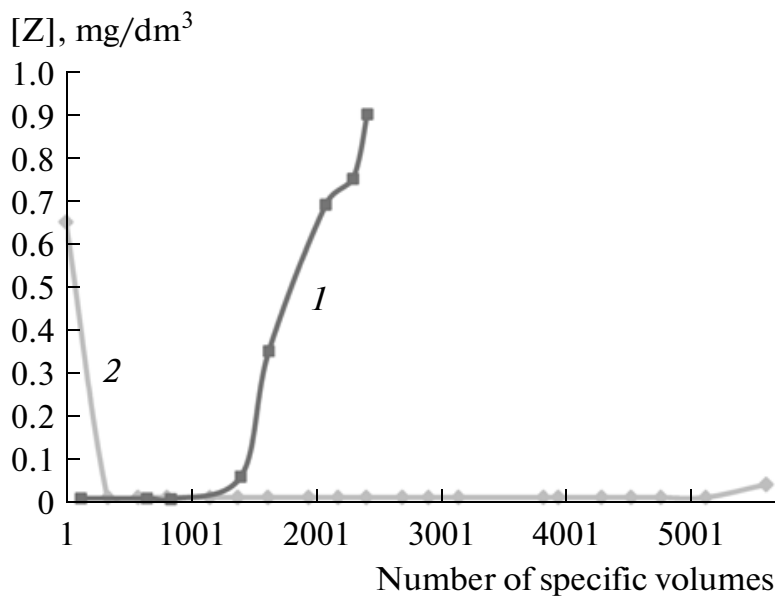

Fig. 2. Resulting zinc sorption curves. (1) Disodium of the ion exchanger and (2) hydrogen form of the ion exchanger.

the prebreakthrough degree of purification was higher than $99 \%$.

The Lewatit TP-207 ion exchanger ensures the recovery of zinc ions according to the required MAC and has the maximal capacity DEC $=21.7 \mathrm{~g} / \mathrm{dm}^{3}$ and $F D E C=47.9 \mathrm{~g} / \mathrm{dm}^{3}$. It is this sorbent that underwent extended testing. The material capacity was $1 \mathrm{dm}^{3}$. The ion exchanger was put into two cascade-connected sorptive columns in the amount of $0.5 \mathrm{dm}^{3}$ into each. The two-step purification was chosen for the selective absorption of elements, namely, copper at the first step and zinc at the second step.

Like in laboratory testing, zinc was the sorptionlimiting impurity used in the extended testing (Fig. 2).

The dynamic capacity of the ion exchanger in regards to zinc both in the disodium and hydrogen forms was $14.6 \mathrm{~g} / \mathrm{dm}^{3}$ of the material. The increase in the filtering cycle in the second case was due to the decrease in the zinc content in cold water. Thus, it was found that the form of the ion-exchanger charge does not affect the sorption efficiency of zinc.

If the $\mathrm{H}^{+}$ion exchanger was used, the $\mathrm{pH}$ of purified water compared to the starting water decreases from $6.6-8.1$ to 2.7 and then gradually rises to 7.1 at the breakthrough instant. The minimal posttreatment $\mathrm{pH}$ of water for the $\mathrm{Na}^{+}$ion exchanger was 5.8.

Thus, a posttreatment water neutralizer should be foreseen if the $\mathrm{H}^{+}$material is used. However, hydrogen ion exchangers are preferable because they make it possible to combine the elution with the regeneration and exclude the introduction of additional alkaline reagents.

If the content of hardness ions exceeds the content of copper and zinc ions when the first (about 20-30) specific volumes are passed, calcium and magnesium 
Results of experiments for selecting the ion exchanger

\begin{tabular}{|c|c|c|c|c|c|c|c|c|c|}
\hline \multirow{2}{*}{ Ion exchanger } & \multicolumn{4}{|c|}{ Static exchange capacity (SEC), g/dm ${ }^{3}$} & \multirow{2}{*}{$\begin{array}{c}\text { Total capacity } \\
\text { of ion exchanger, } \\
\mathrm{g} / \mathrm{dm}^{3}\end{array}$} & \multicolumn{2}{|c|}{$\begin{array}{l}\text { Distribution } \\
\text { coefficient }\end{array}$} & \multirow{2}{*}{$\begin{array}{c}\text { Separation } \\
\text { coefficient } \\
D_{\mathrm{Zn} / \mathrm{Ca}}\end{array}$} & \multirow{2}{*}{$\begin{array}{c}\text { Recovery } \\
\varepsilon_{\mathrm{Zn}}, \%\end{array}$} \\
\hline & $\mathrm{Cu}$ & $\mathrm{Zn}$ & $\mathrm{Ca}$ & $\mathrm{Mg}$ & & $K_{\mathrm{Zn}}$ & $K_{\mathrm{Ca}}$ & & \\
\hline KU-23 & 0.018 & 1.68 & 32.8 & 1.8 & 36.3 & 90.8 & 91.3 & 0.99 & - \\
\hline Amberlite IR-120 & 0.018 & 1.72 & 41.6 & 2.56 & 45.9 & 95.0 & 113.8 & 0.83 & - \\
\hline VP-1p & 0.025 & 1.88 & 2.64 & 0.3 & 4.84 & 129.8 & 7.6 & 16.98 & 10.3 \\
\hline Tulsion CXO-12MP & 0.025 & 1.79 & 7.6 & 0.6 & 10.01 & 117.6 & 21.5 & 5.47 & 5.6 \\
\hline Purolite S984 & 0.025 & 7.43 & 5.2 & 0.296 & 12.95 & 1867.5 & 14.2 & 131.08 & 75.3 \\
\hline Purolite S930 Plus & 0.025 & 7.59 & 25.2 & 1.2 & 34.01 & 1317.3 & 96.6 & 13.64 & 64.2 \\
\hline Lewatit TP-207 $\left(\mathrm{H}^{+}\right)$ & & & & & & & & & \\
\hline Monoplus XL & 0.025 & 7.34 & 10.4 & 0.72 & 18.49 & 1428.5 & 22.2 & 64.49 & 68.1 \\
\hline Lewatit TP-207 $\left(\mathrm{Na}^{+}\right)$ & & & & & & & & & \\
\hline Monoplus XL & 0.025 & 8.40 & 15.6 & 1.04 & 25.06 & 2529.4 & 25.4 & 99.39 & 79.4 \\
\hline Tulsion CH-90 $\left(\mathrm{Na}^{+}\right)$ & 0.025 & 8.94 & 20.4 & 1.08 & 30.44 & 4535.5 & 52.6 & 86.26 & 87.8 \\
\hline KFGM-7 (active) & 0.025 & 1.24 & - & - & 1.27 & 111.5 & - & - & 30.8 \\
\hline KFGM-7 (inactive) & 0.025 & 1.51 & - & - & 1.54 & 150.3 & - & - & 37.5 \\
\hline
\end{tabular}

Note: Ratio $\mathrm{S}: \mathrm{L}=1: 500$; the sorption period is 7 days.

are mainly absorbed. During sorption, hardness ions are forced out from ion exchangers by heavy metals, the content of which decreases to the MAC.

The ion exchangers were directed to regeneration when the breakthrough over the limiting impurity of zinc occurred. If the ion exchanger was desorbed with sulfuric acid in a concentration of $150 \mathrm{~g} / \mathrm{dm}^{3}$, the regeneration degree was $99.9 \%$ and the zinc concentration in the eluate was $21.1 \mathrm{~g} / \mathrm{dm}^{3}$; i.e., a 1000 -fold concentration of zinc is possible during regeneration. The resulting eluates were directed for the sedimentation of $\mathrm{Zn}$ with the $\mathrm{Na}_{2} \mathrm{CO}_{3}$ solution.

\section{CONCLUSIONS}

The volume processed during the tests is $11 \mathrm{~m}^{3}$, and the results are as follows: the recovery is $99.9 \%$; the metal content in purified water, $\mathrm{mg} / \mathrm{dm}^{3}$, was $<0.001 \mathrm{Cu}$ and $<0.01 \mathrm{Zn}$.
It is planned to use results in the development of the general neutralization technology of mine water. Purified water may be discharged into natural basins or used for technological purposes in the water-circulation system.

\section{REFERENCES}

1. Markov, V.F., Formazyuk, N.I., and Maskaeva, L.N., Mezhdunar. Nauch. Zh. Al'ternat. Energet. Ekol., 2007, no. 3, p. 47.

2. Ashirov, A., Ionoobmennaya ochistka stochnykh vod (Ion-Exchange Purification of Waste Water), Leningrad: Khimiya, 1983.

3. Parshina, I.N. and Stryapkov, A.V., Vestn. OGU, 2003, vol. 5.

4. Dabrowski, A., Chemosphere, 2004, vol. 56, pp. 91106.

5. Lebedev, K.B., Ionity $v$ tsvetnoi metallurgii (IonExchange Resins in Nonferrous Metallurgy), Moscow: Metallurgiya, 1975. 